\title{
Grit within the Context of Career Success: a Mixed Methods Study
}

\author{
Rachael S. Clark ${ }^{1}$ (I) - Vicki L. Plano Clark $^{2}$
}

Accepted: 22 August 2019 / Published online: 2 September 2019

(C) Springer Nature Switzerland AG 2019

\begin{abstract}
Grit has been shown to predict success in several achievement-related domains but had not been studied in the career context. This mixed methods study examined whether grit predicted career success and explored the role and relevance of grit in career success for gritty, successful working adults. Four hundred twenty-three adults participated in the quantitative phase and provided survey responses to the Short Grit Scale (Grit-S), the Career Satisfaction Scale (CSS), a career status measure, and salary information. Quantitative data were analyzed using correlational analysis, independent samples t-test, one-way ANOVA, and multiple regression. In this study, the correlational analysis showed that grit did not predict career success. Multiple regressions demonstrated that grit did not significantly add to any of the models using age and gender as covariates. Five individuals from the quantitative phase agreed to participate in the qualitative phase and were invited based on their top quartile scores on the Grit-S and CSS. Individual interviews served as the qualitative data collection method, and text data were analyzed using principles of positive psychology as a theoretical framework. Findings suggest that although gritty, successful participants perceived grit as necessary for their career success, they did not think it was sufficient. Participants named luck, opportunity, and networking as more important than grit in their success.
\end{abstract}

Keywords Grit · Career success · Mixed methods · Positive psychology $\cdot$ Sequential

Electronic supplementary material The online version of this article (https://doi.org/10.1007/s41042-01900020-9) contains supplementary material, which is available to authorized users.

Rachael S. Clark

clarkr7@nku.edu

1 Department of Psychological Science, Northern Kentucky University, 1 Nunn Drive, Highland Heights, KY 41099, USA

2 College of Education, Criminal Justice, and Human Services, University of Cincinnati, 638N

Teachers College, Cincinnati 45221 OH, USA 
The study of flourishing, most closely aligned with the field of positive psychology, focuses on identifying characteristics and experiences that lead to optimal human functioning (Seligman and Csikszentmihalyi 2000). Character strengths such as grit and resilience are considered pathways to well-being (Robertson et al. 2015) and some strengths are known to produce positive outcomes in the form of achievement (Niemiec 2017; Seligman 2011). Grit, defined as passion and perseverance for long-term goals despite setbacks (Duckworth et al. 2007), has been shown to predict success in several achievement-related domains: teacher effectiveness (Duckworth et al. 2009), high school graduation (Eskreis-Winkler et al. 2014), college grades (Strayhorn 2014), and West Point summer program retention (Duckworth et al. 2007).

Despite the growing interest in and enthusiasm for developing grit in individuals (Hoerr 2013; Tough 2012), evidence of its predictive capacity is mixed. Recent studies have not shown an association between grit and success in non-traditional doctoral students' program completion, or law students' or first-year college student grades (Cross 2013; Kern and Bowling 2015; Stewart 2015). A meta-analysis of 88 samples from grit studies demonstrated that grit only moderately correlates with performance (Crede et al. 2016). Because grit is a relatively new construct, having only been operationally defined and examined within the past 10 years, and because research to date provides a contradictory picture of the role it plays for individuals, it is essential to continue studying the grit construct in a variety of contexts. While the science of achievement moves forward, it is important to examine the underlying mechanism of how grit operates, in what contexts it manifests, and how it is perceived by individuals who exhibit the trait. Grit's predictive ability may then be better understood from a practical standpoint so that workers can understand the importance and relevance of grit in their own workplace.

Grit is currently conceptualized as a personality trait (Duckworth et al. 2007) and therefore it is assumed that gritty individuals exhibit the characteristic across situations. Most studies of grit use only quantitative methods, which limits our understanding of grit to what may be measured with numbers (Duckworth et al. 2007; Duckworth and Quinn 2009; Eskreis-Winkler et al. 2014; Strayhorn 2014), and does not allow for the examination of contextual differences in the experience of grit (Bryman 2006; Plano Clark and Ivankova 2016). It is unknown whether individuals experience grit differently across domains, and if so, how these differences manifest in achievement-related events.

One domain that has not yet been substantially explored with regard to grit's predictive potential is career success. From a positive psychology perspective, it is important to include career success in studies of grit, as careers provide individuals with a sense of identity and meaning (Forest et al. 2011; Kram et al. 2012). Careers are also associated with happiness and productivity (Russell 2008). The only found study of grit and career success defined success as retention of six months at the same job (Eskreis-Winkler et al. 2014). Eskreis-Winkler et al. (2014) found that grit predicted workplace retention above and beyond other variables such as conscientiousness. Because neither objective nor subjective career success were measured within the Eskreis-Winkler et al. (2014) study, it is unknown how grit relates to these different indicators of career success.

To address this gap, this study examined the relationship between grit and career success in a diverse sample of working adults representing a variety of occupations. The relationship between grit and career success was tested, and the role and relevance of grit within the career success experience was explored using a sequential mixed methods design. 


\section{Guiding Perspective}

Positive psychology served as a guiding perspective for this study (Seligman and Csikszentmihalyi 2000) by framing the research design, case selection, and interpreting results and findings. Positive psychology bounded the research through focusing on optimal human functioning (Frazier et al. 2006; Lopez et al. 2015; Seligman 2011), as grit is considered a character strength and one of the backbones of the field (Niemiec 2017; Peterson and Seligman 2004). We found few published grit studies that used a guiding (or theoretical) framework (e.g., Barrington 2018; Coates 2017; Everett 2017), although some studies link grit with personality constructs such as the Big Five (Duckworth and Gross 2014; Eskreis-Winkler et al. 2014), or within more broad constructs such as happiness or well-being (Von Culin et al. 2014). We deliberately used a guiding framework in this mixed methods study to inform the research design and methods of each phase (Creswell and Plano Clark 2011). The use of such a framework is rare (Collins et al. 2007) and can provide guidance in complex investigations (Evans et al. 2011).

This research was further supported by social cognitive theory (Bandura 1978), selfdetermination theory (Deci and Ryan 2008), and social cognitive career theory (Lent et al. 1994). Social cognitive theory (Bandura 1978) and self-determination theory (Deci and Ryan 2008) framed the study of the grit construct. Social cognitive theory holds that three factors work together to create self-efficacy beliefs: personal, behavioral, and environmental. Although the three factors are inherent in the concept of agency, social cognitive theorists acknowledge that humans do not have control over all situations in all domains of their lives. Individuals make decisions about the degree to which they will persist in goal attainment in terms of effort and time commitment (Bandura 1977). Because persistence is a primary element in the definition of grit, social cognitive theory provides a guiding framework for considering how the grit construct may operate in the career domain for working adults (Duckworth et al. 2007).

Self-determination theory is an added approach to studying human development and motivation (Deci and Ryan 2008). Self-determination theory proposes that the desire for personal growth reflects an innate psychological need, and that need is required in order to experience optimal functioning and well-being (Deci and Ryan 1985; Ryan and Deci 2000). Specifically, the requirement for autonomy is considered a basic psychological need because individuals have a need to control their own behavior (Gagne and Deci 2005). Self-determination theory acknowledges the impact of the environment on individual behavior and describes optimal conditions that enhance well-being in the workplace, schools, and relationships (Ryan and Deci 2001). With its acknowledgement of contextual influences on individual behavior, self-determination theory serves as a bridge between the study of the individual and the inclusion of environmental variables in studies of human behavior. For these reasons, selfdetermination theory framed the exploration of the grit construct within a specific contextual domain.

Social cognitive career theory framed the career success concept and experience. Social cognitive career theory was created to integrate various career theories with social cognitive theory (Lent et al. 1994) and to address developmental changes in educational and vocational settings (Lent and Brown 2013). Focusing on how well individuals persevere in the workplace and the level of success they attain despite obstacles are 
major elements in the social cognitive career theory (Lent and Brown 1996). There is an apparent overlap between the definition of grit as passion and perseverance in reaching long-term goals despite setbacks (Duckworth et al. 2007) and the focus on perseverance in the workplace despite obstacles (Lent and Brown 1996) found within social cognitive career theory.

\section{Hypotheses}

This study examined the following hypotheses: (1) there will be a positive quantitative relationship between grit and career success in working adults; (2) gritty individuals may describe qualitative differences in how they experience grit in their careers compared with other domains; (3) the qualitative descriptions of the meaning and relevance of grit in career success will explain aspects of the quantitative results; and (4) the combination of quantitative and qualitative results will provide unique insights that contribute to the understanding of how workers flourish in their careers. These hypotheses were informed by our guiding perspective as well as a review of the literature.

\section{Mixed Methods Design}

Mixed methods research entails the intentional administration of both a quantitative and qualitative research process within the same study in order to better understand a research problem (Bryman 2006; Creswell and Plano Clark 2011; Greene 2007). In a sequential mixed methods study, one phase is implemented first and those results are used to inform the design and process of the second phase. In this study of grit within the career domain, the quantitative phase was implemented first, followed by a qualitative phase to explain the quantitative results. Consistent with the administration of a sequential design (Creswell and Plano Clark 2011; Teddlie and Tashakkori 2009), this article first presents the methods and results for the quantitative phase. It then describes the procedure for connecting the phases followed by the methods and findings for the qualitative phase. It concludes with the integration of both phases in the final discussion.

\subsection{Quantitative Phase: Methods}

The aim of the quantitative phase was to determine if grit predicted career success. This section describes methods of the quantitative phase of the study. All participants provided measures of grit, career success, career status, and demographic information.

Participants Convenience and purposive sampling were used to recruit participants who were at least 18 years old and working full-time $(N=423 ; 75 \%$ female). Participants were recruited primarily through electronic means (e.g., Facebook, Twitter, LinkedIn).

Measures Our guiding framework drove the selection of measures in this study. All measures were designed to assess facets of flourishing. The Short Grit Scale (Grit-S) measures passion and perseverance for long-term goals using a Likert-type scale 
(Duckworth and Quinn 2009). The maximum score on the Grit-S is 5 (extremely gritty), and the lowest is 1 (not at all gritty). The Grit-S demonstrated strong reliability in early research (Duckworth and Quinn 2009), with internal consistency reliability ranging from .73 to .83 in validation studies. The Career Satisfaction Scale (CSS) measures subjective career success (Greenhaus et al. 1990). The CSS includes questions such as "I am satisfied with the success I have achieved in my career" and is measured on a Likert-type scale. The CSS contains five items that are summed to provide scores that range from 5 to 25 . The CSS has demonstrated strong internal consistency $(\alpha=.88)$ in the past (Greenhaus et al. 1990).

Career status was measured in two ways: self-reported salary and self-rank of promotions, leadership, and salary compared to peers. Although salary is a preferred objective measure of career status within a single work setting, its utility is limited when comparing across settings and job types (Dries 2011; Jaskolka et al. 1985). Therefore, career status was also measured in terms of rankings to obtain a comparable career success measure in addition to salary. Rankings were measured using a Likerttype scale with $1=$ Well Below Average and $5=$ Well Above Average. Participants were presented with the stem, "For the following items, please rank your position compared with others in your same career" with "salary level," "total number of promotions," and "being a leader in my field" as prompts. Although the career status measure is not truly objective, it was included as a potentially useful indicator of success that could work across a wide range of career types. Demographic information collected included age, sex, number of years working full-time, occupational type (traditional, non-standard, mix), and job title. Participants were asked if they would be willing to be interviewed, and if so provided an email address.

Procedures After providing informed consent, participants answered survey questions using the Qualtrics platform and typically completed in less than 10 minutes. The research project was approved by the institutional review board at the University of Cincinnati.

\subsection{Quantitative Phase: Results}

Participants ranged in age from 18 to $74\left(M_{\text {age }}=42, S D=11.46\right)$ and had been employed full-time for between 1 and 50 years. Respondents were primarily from the United States (95\%) with $1 \%$ from the United Kingdom and $4 \%$ "other." Participants represented all major occupational categories as set forth by the U.S. Department of Labor (U.S. Department of Labor 2013). Eighty-two percent of the sample provided a written job title, and $78 \%$ selected their occupational category from a drop-down menu. The occupations represented in this sample were strongly diverse compared with most grit research. Our sample included intervention specialists, paraeducators, a breed flock supervisor, Navy midshipman, and payroll coordinator as participants. See Tables 1 and 2 for definitions of occupational type and expanded participant characteristics.

The correlational results for grit and different measures of career success are summarized in Table 3. Contrary to our hypotheses, grit did not demonstrate a significant linear relationship with CSS, career status ranking, or salary. The Pearson's $r$ correlation values were all non-significant for the three measures of career success. 
Table 1 Participant characteristics $(N=423)$

\begin{tabular}{lll}
\hline Quantitative phase participants & $n$ & $\%$ \\
\hline Gender & 98 & 23 \\
Male & 296 & 70 \\
Female & 29 & 7 \\
Missing & & 88 \\
Country of residence & 371 & 1 \\
United States & 5 & 3 \\
United Kingdom & 14 & 8 \\
Other & 33 & 74 \\
Missing & & 6 \\
Occupational type & 312 & 13 \\
Traditional & 24 & \\
Non-standard & 53 & \\
Mix & & \\
\hline
\end{tabular}

Traditional: you progress in an organization through promotions and gauge progress according to movement through the organization (i.e., investment banker, executive, professor, computer programmer, etc. NonStandard: a career with uncertain work tenure, typically part-time, unpredictable work schedules. Usually lack security and the typical employer-sponsored benefits. Typically includes careers in the arts (musician, artist, theater, dance, etc.). Mix: perhaps a traditional full-time career, with non-standard part-time work (i.e., full time job as an attorney, and musician on weekends

Table 2 Occupational categories represented in this sample

\begin{tabular}{lll}
\hline Occupational category & $n$ & $\%$ \\
\hline Education, legal, community services, arts, and media & 154 & $47 \%$ \\
Management, business, and financial & 48 & $15 \%$ \\
Healthcare practitioners and technical occupations & 38 & $11 \%$ \\
Office and administrative support & 23 & $7 \%$ \\
Computer, engineering, and science & 19 & $6 \%$ \\
Sales and related occupations & 18 & $5 \%$ \\
Service occupations & 13 & $4 \%$ \\
Installation, maintenance, and repair & 5 & $2 \%$ \\
Farming, fishing, and forestry & 3 & $1 \%$ \\
Military specific & 3 & $1 \%$ \\
Production occupations & 3 & $1 \%$ \\
Transportation and material moving & 2 & $1 \%$ \\
Construction and extraction & 2 & $1 \%$ \\
Missing data & 92 & $22 \%$ \\
\hline
\end{tabular}

Non-imputed data. Categories from U.S. Census Bureau 
Table 3 Pearson's r correlations between career success variables, Grit-S (total scores and subscale scores)

\begin{tabular}{llll}
\hline & Grit-S ( $p$ value) & $\begin{array}{l}\text { Perseverance of effort } \\
\text { subscale }(p \text { value })\end{array}$ & $\begin{array}{l}\text { Consistency of interest } \\
\text { subscale }(p \text { value })\end{array}$ \\
\hline Career satisfaction (CSS) & $.04(.48)$ & $-.02(.72)$ & $-.04(.45)$ \\
Career status ranking & $.01(.86)$ & $.01(.85)$ & $.01(.90)$ \\
Salary & $-.001(.99)$ & $.01(.89)$ & $-.01(.91)$ \\
\hline
\end{tabular}

Imputed data. $N=423$

To understand the correlational results, scatterplots of the major variables were examined. See Online Resource Fig. 1 for scatterplot figures. The scores for the three career success measures covered the range from low to high. Specifically, the CSS scores ranged from 1.40-5.00 $(M=3.88, S D=.78)$, the salary scores ranged from $\$ 7500-\$ 150,000$ or higher $(M d n=\$ 62,500)$, and the career status ranking ranged from $1.00-5.00(M=3.19, S D=.69)$. In contrast, no scores at the low end of the Grit-S were produced, which ranged from $2.25-4.88(M=3.73, S D=.52)$.

Because the predictor and outcome variables did not share a linear relationship, the types of additional analyses that could be performed were limited. Based on previous research that indicated that grit increased with age (Duckworth et al. 2007) and that grit differed by gender (Eskreis-Winkler et al. 2014), a multiple regression on each career success measure (career status ranking, salary, and CSS) was conducted with age and gender as covariates. See Tables 4, and 5 for multiple regression results. There was no relationship between grit, age, and gender on career satisfaction as measured by the CSS. Age was positively related to career status ranking; age and being male related to a larger salary. Surprisingly, grit did not add significantly to any of the regressions when used as a predictor variable (Table 6).

Because grit had only been studied in high-achieving populations (e.g., Duckworth et al. 2007; Duckworth and Quinn 2009; Eskreis-Winkler et al. 2014) and it is unclear how grit manifests across domains, a one-way ANOVA was performed to determine if Grit-S scores varied according to type of occupation (traditional, non-standard, or mix). There were no significant differences in Grit-S scores between the occupational types in

Table 4 Summary of multiple regression analysis on career status ranking

\begin{tabular}{lcccc}
\hline Variable & \multicolumn{1}{c}{$B$} & $\mathrm{SE}_{\mathrm{B}}$ & $\beta$ & Sig. \\
\hline Intercept & 2.78 & .30 & & \\
Grit & .03 & .07 & .02 & .69 \\
Age & .01 & .003 & .14 & $.01^{*}$ \\
Gender & -.06 & .08 & -.04 & .45 \\
$\mathrm{R}=.021$ & & & & \\
Adjusted $\mathrm{R}^{2}=.014$ & & & & \\
\hline
\end{tabular}

$* p<.05 ; B=$ unstandardized regression coefficient; $\mathrm{SE}_{\mathrm{B}}=$ Standard error of the coefficient; $\beta=$ standardized coefficient 
Table 5 Summary of multiple regression analysis on salary

\begin{tabular}{lllll}
\hline Variable & $B$ & $\mathrm{SE}_{\mathrm{B}}$ & $\beta$ & Sig. \\
\hline Intercept & $22,429.79$ & $13,675.31$ & & \\
Grit & 1825.86 & 2995.55 & .03 & .54 \\
Age & 1151.03 & 141.26 & .37 & $.000^{*}$ \\
Gender & $-11,850.17$ & 3672.79 & -.15 & $.001^{*}$ \\
$\mathrm{R}=.411$ & & & & \\
Adjusted $\mathrm{R}^{2}=.163$ & & & & \\
\hline
\end{tabular}

$* p<.05 ; B=$ unstandardized regression coefficient; $\mathrm{SE}_{\mathrm{B}}=$ Standard error of the coefficient; $\beta=$ standardized coefficient

this study $F(2,420)=1.81, p=.166$. An independent samples t-test showed no significant differences reported between males $(M=3.74, S D=0.51)$ and females $(M=3.72$, $S D=0.52), p=.76$.

\section{Connection from Quantitative Phase to the Qualitative Phase}

Quantitative results indicating no relationship between grit and career success were contrary to the stated hypotheses; therefore, the qualitative phase became important in explaining grit's relationship to career success. After the quantitative data were analyzed, the results were connected with the development and refinement of the qualitative phase; in a mixed methods study this is called the point of interface (Creswell and Plano Clark 2011). The principles of positive psychology and the quantitative results were used to guide the selection of participants for inclusion in the qualitative phase, to design the qualitative phase, and to determine interview questions. Because positive psychology encourages the scientific study of optimal functioning, individuals who volunteered to be contacted again and who scored in the top quartile in both grit and career success $(n=15)$ were invited to participate in the qualitative phase. Five agreed to be interviewed. The interview questions were designed to align with the principles of positive psychology by focusing on the optimal aspects of participants' careers, and to understand how gritty individuals experience their grittiness in the context of their career success.

Table 6 Summary of multiple regression on CSS

\begin{tabular}{lllll}
\hline Variable & $B$ & $\mathrm{SE}_{\mathrm{B}}$ & $\beta$ & Sig. \\
\hline Intercept & 3.29 & .34 & & \\
Grit & .06 & .07 & .04 & .39 \\
Age & .006 & .003 & .08 & .09 \\
Gender & .14 & .09 & .08 & .12
\end{tabular}

$\mathrm{R}=.110$

Adjusted $\mathrm{R}^{2}=.005$

$* p<.05 ; B=$ unstandardized regression coefficient; $\mathrm{SE}_{\mathrm{B}}=$ Standard error of the coefficient; $\beta=$ standardized coefficient 


\subsection{Qualitative Phase: Methods}

The aim of the qualitative phase was to examine the mechanism of how grit operates, in what contexts it manifests, and how it is perceived by individuals who exhibit the trait. Because grit had been shown to predict success in other domains, one of the major objectives of the qualitative phase was to attempt to explain why grit did not predict career success in this sample of working adults by administering an in-depth individual interview. A secondary objective was to explore the relevance and meaning of grit for gritty, successful people.

Sample Data were collected from five gritty, successful individuals using one-on-one interviews. The five interviewees were purposefully selected to contribute to the study of optimal human functioning and understanding of grit in the domain of career success. Pseudonyms were used for each participant.

Data Collection and Analysis Guided by the principles of positive psychology, we designed the interview protocol to elicit information about the experience of grit in the participants' career success. The interview protocol consisted of eight open-ended questions as well as probes and follow-up questions. The protocol was revised based on an iterative process aimed at encouraging participants to elaborate on responses or providing more information. Example of interview questions included, "How have passion and perseverance influenced your career success?" and "Some people call drive and persistence 'grit.' How does this term 'grit' apply to your career success?" Participants were specifically asked about their understanding of the term grit in order to assess the construct validity of the term and to determine the extent to which grit applied to success in multiple contexts.

Data were analyzed inductively using pattern codes and deductively using theoretical frameworks (Braun and Clarke 2006; Miles et al. 2014). Findings from the qualitative analysis in the form of subthemes and different perspectives are described according to major categories: grit, career success, and the relationship between the two.

The data analysis process was iterative and involved several rounds of coding. For readability, the process is depicted in a linear fashion. We used a theoretical thematic analysis approach to analyze the qualitative data, which is a flexible method used to identify patterns in data (Braun and Clarke 2006). In the first round of coding, we coded the transcripts completely on an emergent basis. The first round of coding resulted in 87 individual codes. Examples of codes that emerged in this phase included "internal drive," and "perceived as hard worker." For the second round, we used the three additional theoretical frameworks used to structure the study: social cognitive theory, self-determination theory, and social cognitive career theory. The theory-guided coding resulted in 52 individual codes including, "Self-Determination Theory: Competence" and "Positive Psychology: Personal Fulfillment." In the third round of coding, we used a semantic thematic analysis (Braun and Clarke 2006) which focuses on the meaning of qualitative data across cases. Because we were interested in the meaning that interviewees assigned to the grit construct, and how the experience of grit may have influenced career success, we created two major categories a priori in the third round of coding: grit and career success. Subthemes about each category emerged from the data analysis. 
After the final round of coding, we created a thematic map to assist with interpreting the findings (Braun and Clarke 2006). A thematic map is a tool for facilitating qualitative data analysis and illustrates the relationship between codes and themes. A thematic map resembles a flowchart; shapes contain themes (e.g., Career Success) or subthemes (e.g., Role of Passion and Grit Relevant Outside the Workplace) and arrows connect the shapes illustrating the relationship between and among the themes (e.g., Career Success > Managers Favored Objective Markers of Success > Salary, Bonuses, Promotions). Additionally, we created a causal chain and conceptually clustered matrix to assist in the interpretation of findings about grit (Miles et al. 2014). The causal chain illustrated a series of events in order and illustrated the relationship between the variables involved in career success according to the analysis. The conceptually clustered matrix served as a data management tool and an analysis tool. See Online Resource Figs. 2, 3, and 4 for the thematic map, causal chain and conceptually clustered matrix.

\subsection{Qualitative Phase: Findings}

Participants Five individuals from the quantitative phase with grit and career success scores in the top quartile volunteered to participate in the qualitative phase. Three worked in business-related occupations and two worked in higher education settings. See Table 7 for descriptive information about participants in the qualitative phase.

Grit Grit was defined differently by each participant, generally specific to their place of employment. All interviewees stated that grit was important to their career success, but none considered it to be the most important factor in their success, which aligns with the non-significant quantitative results from the first phase. Contextual influences on the grit experience seemed evident, as grit was described differently by interviewees specific to their individual workplace suggesting that context may determine how the grit experience manifests differently depending on the situation.

Manifestation of Grit Specific to Individual Grit was largely defined by interviewees as hard work. Three interviewees described grit as either having a strong work ethic or working long hours. For example, Eric, an Assistant Professor, described grit in his workplace as responding to student emails quickly. He described grit as "working non-

Table 7 Descriptive information for participants in the qualitative phase

\begin{tabular}{llllll}
\hline Participant* & Age & Gender & Grit-S Score & CSS Score & Occupation \\
\hline Olivia & 30 & F & 4.25 & 4.8 & Program Coordinator \\
Jason & 40 & M & 4.13 & 4.8 & Assistant Professor \\
Eric & 28 & M & 4.63 & 5.0 & Assistant Professor \\
Lauren & 44 & F & 4.38 & 4.8 & Quality Manager \\
Scott & 39 & M & 4.50 & 4.0 & Senior Risk Consultant \\
\hline
\end{tabular}

*Pseudonyms 
stop" and modeled his own work ethic after his father and brother, who worked "all the time." Scott, a Senior Risk Consultant, compared grit to the "daily grind" and recalled applying grit in the early days of his career when he joked with coworkers who left at 5:00, "You taking a half day?" Within each workplace, peer pressure seemed to influence these interviewees to demonstrate grit. Olivia noted that she worked in a small office and stated that if her coworkers did not "pull their weight" it would not be accepted.

For the interviewees in this study, grit seemed to be expected in the workplace. Jason said grit was "just what you should do...it's like the minimum." The common thread between the interviewees' experiences with grit was that if you did not demonstrate grit in the workplace, someone else would.

Career Success The career success category explored experiences relevant to the grit and career success domain and in order to examine the relevance of grit to career success. The interview data suggested that interviewees' perception of career success varied according to their field of employment.

Relationship between Grit and Career Success The literature-based conceptualization of grit includes the elements of passion, perseverance, and long-term goals. These three elements were explored within individual interviews to determine the personal relevance of those constructs to the gritty, successful participants. Overall, individuals connected with perseverance more than passion as relevant to their own success.

Role of Perseverance in Career Success The participants related to the concept of perseverance as relevant to their career success; however, they named other factors they perceived as more important. For example, Jason, an Assistant Professor, believed he had opportunities others had not and thought they were more relevant to his success. Eric described the process of obtaining his first teaching job as a chance meeting with another professor at a conference which led to an instructor position, and eventually a tenure-track position. Eric related perseverance to his decision to continue teaching despite numerous grant rejections and some poor teaching evaluations early in his career.

Role of Passion in Career Success The relevance of passion to career success was explored through direct questioning in the qualitative phase. The Consistency of Interest subscale of the Grit-S is considered a measure of passion (Duckworth and Quinn 2009). Interviewees rarely mentioned passion without being directly asked about how the term resonated with them. Some found passion a distraction from their career path, 'I don't like that word [passion] because it...doesn't sound sustainable... Burn too bright too fast. Like, I want to be consistent" (Jason). Scott described passion as a concept at the opposite end of a continuum from grit, "...if you are excited and passionate about what you're doing, grit is the last thing that's on your mind. I guess if grit's on one end, passion is pulling you to the other side." Olivia also seemed to separate passion from grit, "You said earlier that some people call this thing passion, which really isn't the same...it's not really the same thing as grit."

Although most interviewees $(n=4)$ did not find passion relevant to their career success, they consistently drew upon "drive" to "get them through" after failing at a 
job-related task. "If I...didn't have the drive to go in and get there early, stay late, know that there would be some sort of reward on the end..." (Scott). Eric described an "internal drive" to succeed in his teaching position by responding to students concerns quickly and by using course evaluations to improve his teaching. Passion seemed somewhat confusing to interviewees as a contributor to career success and they related more to the term "drive." The interview data suggest that interviewees did not perceive passion as synonymous with Consistency of Interest.

Grit Perceived as Foundation to Career Success When asked directly if grit contributed to their career success, all five interviewees stated that it did. However, several individuals qualified their statements by stating that grit was not enough to be successful in your career. Luck, networking, and opportunity were factors that interviewees mentioned as assisting in their career success on top of being gritty. The interview data suggested that gritty participants viewed grit as a foundation upon which career success builds, with other contributing factors at least as important as grit. Refer to Online Resource Fig. 5 for a model of grit's role in career success according to the gritty, successful individuals in this study.

\section{Integration}

We entered data, results, and findings from the major analyses of each phase into a table called a joint display in order to facilitate interpretation of both strands and to create meta-inferences. A joint display is both a method and device for facilitating the integration of quantitative and qualitative data (Greene 2007). Data were included from the major quantitative analyses, and qualitative findings that addressed each quantitative result to better integrate the two phases of this study. Creating meta-inferences is key in a mixed methods study, because meta-inferences attempt to respond to the mixed methods research questions (Teddlie and Tashakkori 2009). See Table 8 for the joint display.

Results and findings in the joint display are organized according to major research question. The second column displays results of quantitative analysis, and the third column shows quotes from the qualitative data that explain the quantitative results. The fourth column contains interpretations of the integration of quantitative results with qualitative findings. The joint display helped us understand that participants defined grit differently than it was measured and that grit manifested differently in each workplace.

\section{Discussion}

The results in this study diverged from previous work that indicated a moderately strong relationship between grit and success (Duckworth et al. 2007, 2010; EskreisWinkler et al. 2014, Strayhorn 2014); however, the results aligned with recent studies reporting correlations between grit and academic success, well-being, and military contract commitment near zero (Chang 2014; Datu et al. 2015; Jordan et al. 2015). 
Table 8 Joint display comparing quantitative results and qualitative findings for the elements of the grit construct

\begin{tabular}{|c|c|c|c|}
\hline $\begin{array}{l}\text { Elements of grit } \\
\text { (Duckworth and } \\
\text { Quinn 2009) }\end{array}$ & $\begin{array}{l}\text { Instrument topics } \\
\text { (Duckworth and } \\
\text { Quinn 2009) }\end{array}$ & Quantitative results & $\begin{array}{l}\text { Qualitative findings in career } \\
\text { context }\end{array}$ \\
\hline $\begin{array}{l}\text { Consistency of interest } \\
\text { (Passion) }\end{array}$ & $\begin{array}{l}\text { 1. Goal continuity. } \\
\text { 2. Project fidelity. } \\
\text { 3. Project focus. } \\
\text { 4. Project completion. }\end{array}$ & $\begin{array}{l}\alpha=.73 \\
M=3.39(.73) \\
\text { Range }=1-5 \\
r(421)=-.04, p=.45 \\
\quad(\text { Consistency of } \\
\quad \text { Interest/CSS } \\
\quad \text { correlation) }\end{array}$ & $\begin{array}{l}\text { - Three participants considered } \\
\text { passion and grit separate constructs } \\
\text { - "Drive" considered more relevant } \\
\text { to career success } \\
\text { - Three participants considered } \\
\text { "drive" a trait }\end{array}$ \\
\hline $\begin{array}{l}\text { Perseverance of effort } \\
\quad \text { (Persistence) }\end{array}$ & $\begin{array}{l}\text { 1. Finishing tasks. } \\
\text { 2. Discouragement } \\
\text { from setbacks. } \\
\text { 3. Diligence. } \\
\text { 4. Work ethic. }\end{array}$ & $\begin{array}{l}\alpha=.47 \\
M=4.07(.49) \\
\text { Range }=3-5 \\
r(421)=-.02, p=.72 \\
\quad \text { (Perseverance of } \\
\quad \text { Effort/ CSS } \\
\quad \text { correlation) }\end{array}$ & $\begin{array}{l}\text { - All participants noted } \\
\text { perseverance as essential to } \\
\text { career success } \\
\text { - Relevant outside of work for success } \\
\text { as well as within career context } \\
\text { - Experienced as "hard work" by } \\
\text { participants }\end{array}$ \\
\hline Long-term goals & $\begin{array}{l}\text { 1. Goal achievement } \\
\text { for extended } \\
\text { projects. }\end{array}$ & - & $\begin{array}{l}\text { - Three participants did not set } \\
\text { long-term goals and found them } \\
\text { annoying or constricting } \\
\text { - One participant was in the midst } \\
\text { of reevaluating career goals due } \\
\text { to her pregnancy } \\
\text { - One participant, a college professor, } \\
\text { set long-term goals for achieving } \\
\text { tenure-related markers }\end{array}$ \\
\hline Setbacks & $\begin{array}{l}\text { 1. Attained goal } \\
\text { despite setbacks. }\end{array}$ & - & $\begin{array}{l}\text { - One participant identified } \\
\text { negative feedback from } \\
\text { scholarly journals as a potential } \\
\text { setback early in career } \\
\text { - Four participants did not mention } \\
\text { overcoming setbacks as part of } \\
\text { demonstrating grit; direct } \\
\text { questioning did not produce any } \\
\text { insights in this area }\end{array}$ \\
\hline
\end{tabular}

In the qualitative phase, gritty, successful individuals were interviewed to explore the relevance of grit in their career success. Findings from the qualitative phase indicated that interviewees perceived grit differently than it was measured; most defined grit as working hard or having a strong work ethic and necessary for career success. Setting long-term goals and the passion construct, both elements of the current definition of grit (Duckworth and Quinn 2009), did not resonate for the four of the five interviewees in this study.

Recent research outcomes align with results from this study in reporting that grit did not predict success within specific domains. Cross (2013) studied academic success in nontraditional doctoral students and did not find a relationship between grit and success. Likewise, Joseph (2009) found no relationship between grit and athletic ability. Finally, grit did not predict first year GPA in college students (Chang 2014). 
It is possible that the career context is sufficiently different from the educational and military settings to necessitate a different measure of grit. The career domain is somewhat unstructured and other characteristics may be more important to succeed. Multiple contexts may shape the experience of grit within career success such as the societal context, occupational category, and individual experience. For example, grit may look quite different for a teacher compared to a quality manager or a nurse. Crede et al. (2016) suggested that grit may predict success in well-defined situations and be less predictive in "ill-defined", "novel" contexts, which aligns with the results from this study (p. 2). In addition, all interviewees in the qualitative phase, and most participants in the quantitative phase, were American. It is possible that participants did not perceive grit as a predictor of career success due to the strong focus on work ethic in the American cultural value system. Because this study's sample largely represented individuals with at least moderate levels of grit, which in itself indicates a level of success, it is possible that they had more opportunities to network with other gritty individuals, more opportunities for career advancement, or other advantages that lowgrit individuals did not have. Perhaps the presence of grit contributes to a positive feedback loop in which gritty behavior leads to opportunities, which is then reinforced with objective measures of career success such as promotions and salary increases. In that case, people with low levels of grit would not be exposed to factors that lead to career success.

\subsection{Theoretical Contributions}

Positive psychology was used as a lens through which to frame the research design, case selection, and interpretation of results and findings. Using positive psychology as a guiding framework provided an "organizing structure" to frame the phases of this mixed methods study (Evans et al., p. 278). As a guiding framework, positive psychology first informed the topic chosen for this study. Grit is considered a character strength, and using one's character strength strongly relates to the experience of flourishing and experiencing optimal human functioning (Proctor et al. 2009). Character strengths are considered the backbone of positive psychology, and the study of grit directly supports the creation of knowledge in a domain considered foundational to the discipline.

Next, positive psychology served as a framework for the research design process. At several points throughout the sequential explanatory study, decisions were made that impacted case selection and the design of phases of research. For example, after the quantitative phase was administered and data analyzed, the qualitative phase was designed and a case selection strategy chosen for interview invitations. Studying only high performers, in this case participants in the top quartile, provided an understanding of the role of grit in career success for people who are gritty and successful.

Self-determination theory was used to frame the study of grit in this study. Selfdetermination theory acknowledges the impact of the environment on behavior and focuses on the experience of well-being and optimal functioning (Deci and Ryan 2008; Ryan and Deci 2000; Sheldon and Ryan 2011). According to the quantitative results of this study, the correlation between grit and career success was near zero for full-time working adults; these results could indicate that there were other variables not included in the analysis that had a significant influence on career success. According to self- 
determination theory, the outside influences responsible for success could stem from the impact of the environment on behavior. Additionally, self-determination theory describes the need for personal growth, and states that humans have a need for autonomy, relatedness, and competence (Deci and Ryan 2008). Findings from the qualitative phase support the theory of self-determination. The three educators described the importance of liking their coworkers, consistent with the element of relatedness. The two managers measured success in terms of how the quality of their work improved over time, thus supporting the element of competence.

Cognitive, personal, and environmental elements combine to form the basis of social cognitive career theory (Lent et al. 1994). The personal element of social cognitive theory was explored through the measurement of grit and exploration of the construct within the career success context. Social cognitive career theory addresses developmental changes in vocational settings (Lent and Brown 2013); several participants mentioned that their definition of career success changed over time according to the demands of their family life. Achieving success seemed to be a moving target throughout these participants' careers, and a workplace that adapted to these changes was highly valued.

The cognitive element in social cognitive career theory relates to agency, which may be conceptualized as intentionality (Bandura 2001). The cognitive aspect of social cognitive career theory was supported in part by the qualitative findings in this study. Participants described their career success as being due in part to taking advantage of opportunities. The environmental aspect of social cognitive career theory was also supported in part by the qualitative findings. Some participants described being around other gritty people as having a strong impact on their own level of grit. Hardworking parents, coworkers exhibiting grit, and even spouses who demonstrated grit had a positive impact on the participants in motivating them to persevere in the workplace.

\subsection{Methodological Contributions}

Theoretically, the positive psychology framework guided decisions at every major phase of this research project. One of the major methodological contributions this study makes is in sampling theory. For example, after the quantitative phase, the principles of positive psychology guided the selection of participants for the qualitative phase. The science of positive psychology aims to produce knowledge about optimal functioning in order to assist people, communities, and institutions in actualizing their potential. Overall, the objective of this science is to uncover contexts, experiences, mindsets, and cultures that encourage thriving. Sampling from a strengths-based perspective allows researchers to study individuals with a great degree of the construct under study, and from whom we can best learn about the science of thriving. In human participants research, sampling procedures have often focused on obtaining a sample that is broad in nature and generalizable to the larger population. Probability sampling increases the likelihood that the average individual is well-represented. The downside of probability sampling, according to positive psychology principles, is that increasing the knowledge base on the average experience perpetuates mediocrity. Positive psychology was ideal as a guiding framework in this sequential design because the objective was to both confirm and explore extraordinary experiences. Because the study focused on how the grittiest workers experienced grit in career success, we based 
sampling decisions on the principles of positive psychology. In the qualitative phase in this sequential design, positive psychology directed the inclusion criteria in order to focus on the participants who were experiencing the very best possible outcomes in their careers - those at the extreme end of the normal curve, sometimes considered outliers. Had probability sampling been used, the obtained results may have been a scattered sample of individuals with various levels of grit and career success. The participants from a probability sample may not have provided information on what it means to flourish in one's career.

In terms of conducting mixed methods research, the framework served to bound the findings, and ensure they were relevant to the research questions. Positive psychology principles also kept the study framed according to the major objectives. Although interesting questions emerged based on the results and findings, not all aligned with the purpose of the study. Therefore, in order to most efficiently answer the research questions, the qualitative follow-up focused on emerging questions that directly related to advancing knowledge about flourishing.

Another methodological contribution this study makes is in advocating for the use of a theoretical framework in mixed methods research. Theories are not used extensively in mixed methods research (Collins et al. 2007). In the years 2004-2010, only 28 mixed methods studies used such a lens to frame the research design a priori (Evans et al. 2011). One of the drawbacks of the absence of a guiding framework is that future mixed methods researchers do not have sources to draw upon when creating their own studies. Another drawback of not using a theoretical framework is that the quantitative and qualitative data may be poorly integrated (Evans et al. 2011). Using a theoretical framework in mixed methods research provides a guide through the "low, swampy ground" (Schon 1987, p. 3) of real-world problems. The use of a theoretical framework could provide guidance in mixed methods investigations, which can be complex and may require shifts in subjectivity and objectivity throughout the study or series of studies (Evans et al. 2011). Mixed methods studies also embody several phases or strands, which may be navigated more efficiently using a theory to inform the design and methods of each phase (Creswell and Plano Clark 2011).

Positive psychology provides a unique framework that especially aligns with the sequential mixed methods design. Defining flourishing in quantitative terms was straightforward. We designated the top quartile in grit and career success scores as flourishing, and once the flourishers were identified, they were contacted for follow-up interviews in the qualitative phase. The sequential aspect of this mixed methods design aligned well with the aim of understanding the experiences of those experiencing the most grit and career success.

The choice of research topic was the result of considering positive psychology principles in research - studying positive character traits and how they contribute to success rather than studying contributors to career failure. In the quantitative phase, the study of grit and career success illustrated the aim of positive psychology principles. In the qualitative phase, the interview protocol was created based on principles of positive psychology to guide the type of information asked for from participants, exclusively focusing on their success and experience with grit.

Those functioning at the very top of the performance spectrum could be studied to influence workplace design and even public health policy. If flourishers are included in mixed methods research, the impact of studying the best possible outcomes for a 
variety of human experiences may exponentially increase. The knowledge base may increase dramatically by administering focused studies on the best outcomes in the human experience. On the basis of these exploratory studies, scientists could then design experimental inquiries to test the numerous theories and predictions that emerge from the foundational research.

\subsection{Limitations and Future Research}

Self-report survey data may produce a social desirability effect (Nederhof 1985). The Grit-S is fairly transparent, and the desire to appear hardworking may have influenced participants' responses. Future research could include an outside rater in the workplace, for example, who could complete the Grit-S or otherwise report level of grit in the workplace. The outside rating could triangulate results from self-rating scores on the Grit-S.

The range of variation in the quantitative sample was not known at the outset of the study, and largely reflected individuals with moderate to high grit and career success. The inclusion criteria for this study may have limited the generalizability of results and understanding of the role of grit in career success. By including unemployed individuals, for example, it is possible that a wider range of scores on the Grit-S and CSS would have been produced. Future research could allow individuals who were unemployed or who work part-time to participate in the quantitative phase in order to include individuals who may be experiencing low levels of grit and/or career success.

Grit was the single predictor variable measured in this study. The other variables that may contribute to career success were not measured. However, the thematic findings in the qualitative phase may be considered as predictor variables in future research.

Conceptual overlap between grit and hard work seemed apparent for these participants, and were not explored in this study. Recent research demonstrates that work ethic and grit are related constructs sharing 20\% variance (Meriac et al. 2015). Future research should continue to unpack the grit construct and extract the differences between grit and work ethic.

The objective measure of career success was self-reported and therefore not truly objective. Creating an objective measure of career success that is consistent across occupations could be a next step in future research.

\subsection{Practical Recommendations}

The meta-inferences suggest that in order for workers to flourish, not only should they demonstrate perseverance in the workplace, they should be open to opportunities as they arise and network with other professionals. Considering that grit did not predict career success in this study, and that participants in the qualitative phase considered other factors as relevant, additional factors are likely more important in helping workers flourish. The meta-inferences suggest that today's workers would do well do position themselves as hard workers, and to be "open to new experiences," as Kets de Vries (2012) noted from studying stars in organizations for two decades (p. 173). Further, "Tenacity, persistence, perseverance, and determination will almost always beat out raw talent" (Kets de Vries 2012, p. 179), suggesting that gritty workers can be made and are not born. Peterson and Seligman (2004) and Hoerr (2013) also believe that grit is a character strength that can be improved by training individuals to persist and exert effort. 
In this study, grit did not predict career success; therefore, it remains important to explore multiple pathways to success such as networking and building career opportunities. In a similar vein, students enrolled in college courses may consider the findings of this study useful as they plan their career development. Grit has been shown to predict academic success (Duckworth et al. 2007, 2009, 2010; Eskreis-Winkler et al. 2014; Strayhorn 2014). Therefore, it may be helpful to have a gritty personality to obtain college success, and use that success as a foundation on which to build career success. In addition, grit may be more useful in certain jobs and organizations or in the early stages of one's career.

\section{Conclusion}

This study provided insight into the experience of grit within the career success context. The contributions this study makes to the exploration of the grit construct are important, as no other study had used grit as a predictor within the career domain.

It is important to know that grit may not predict career success for full-time working adults. More research should be conducted to replicate and extend the results and findings of this study. In ill-defined environments in which who you know may be as important as what you know, the factors contributing to success in the career domain may be numerous and difficult to pinpoint. It is possible that grit predicts success in concrete, structured situations such as classwork. Once success has been obtained in that domain, individuals must perhaps expand their skill set to include other characteristics and experiences that lead to success, such as social competence, teamwork, and flexibility.

Acknowledgements The authors would like to thank Christopher Cooper, Lori Foote, Laura Kelley, Khahlia Sanders, and Sinem Toraman for feedback on earlier versions of this manuscript.

\section{Compliance with Ethical Standards}

Ethical Approval All procedures performed in the studies involving human participants were in accordance with the ethical standards of the institutional and/or national research committee and with the 1964 Helsinki declaration and its later amendments or comparable ethical standards.

Informed Consent Informed consent was obtained from all individual participants included in the study.

Conflict of Interest The authors declare that they have no conflict of interest.

\section{References}

Bandura, A. (1977). Self efficacy: Toward a unifying theory of behavioral change. Psychological Review, 84(2), 191-215.

Bandura, A. (1978). Reflections on self-efficacy. Advances in Behaviour Research and Therapy, 1(4), $237-269$.

Bandura, A. (2001). Social cognitive theory: An agentic perspective. Annual Review of Psychology, 52(1), 1-26. 
Barrington, M. M. (2018). Assessing the link between grit and academic achievement in reading, mathematics, and writing among 4th graders: An explanatory sequential mixed methods inquiry (Doctoral Dissertation). Retrieved from ProQuest (2042694128).

Braun, V., \& Clarke, V. (2006). Using thematic analysis in psychology. Qualitative Research in Psychology, $3(2), 77-101$.

Bryman, A. (2006). Integrating quantitative and qualitative research: How is it done? Qualitative Research, $6(1), 97-113$.

Chang, W. (2014). Grit and academic performance: Is being grittier better? (Doctoral dissertation). Retrieved from ProQuest (3681407).

Coates, M. C. (2017). Integrating factors of grit in school culture: Case studies of two freshman academies (Doctoral Dissertation). Retrieved from ProQuest. (2004928959).

Collins, K. M. T., Onwuegbuzie, A. J., \& Jiao, Q. G. (2007). A mixed methods investigation of mixed methods sampling designs in social and health science research. Journal of Mixed Methods Research, 1(3), 267-294. https://doi.org/10.1177/1558689807299526.

Crede, M., Tynan, M. C., Harms, P. D. (2016). Much ado about grit: A meta-analytic synthesis of the grit literature. Journal of Personality and Social Psychology. Advance online publication. https://doi.org/10.1037/pspp0000102

Creswell, J. W., \& Plano Clark, V. L. (2011). Designing and conducting mixed methods research (2nd ed.). Los Angeles: Sage.

Cross, T. M. (2013). Staying the course: Grit, academic success, and non-traditional doctoral students (Doctoral dissertation). Retrieved from PQDT Open. (3587687).

Datu, J. A. D., Valdez, J. P. M., \& King, R. B. (2015). Perseverance counts but consistency does not! Validating the short grit scale in a collectivist setting. Current Psychology, 35(1), 121-130.

Deci, E. L., \& Ryan, R. M. (1985). Intrinsic motivation and self-determination in human behavior. New York: Plenum.

Deci, E., \& Ryan, R. (2008). Self-determination theory: A macrotheory of human motivation, development, and health. Canadian Psychologist, 49(3), 182-185.

Dries, N. (2011). The meaning of career success: Avoiding reification through a closer inspection of historical, cultural, and ideological constructs. Career Development International, 16(4), 364-384.

Duckworth, A. L., \& Gross, J. J. (2014). Self-control and grit: Related but separable determinants of success. Current Directions in Psychological Science, 1-7. https://doi.org/10.1177/0963721414541462

Duckworth, A. L., \& Quinn, P. D. (2009). Development and validation of the short grit scale (Grit-S). Journal of Personality Assessment, 91(2), 166-174.

Duckworth, A. L., Peterson, C., Matthews, M. D., \& Kelly, D. R. (2007). Grit: Perseverance and passion for long-term goals. Journal of Personality and Social Psychology, 92(6), 1087-1101.

Duckworth, A. L., Quinn, P. D., \& Seligman, M. E. P. (2009). Positive predictors of teacher effectiveness. The Journal of Positive Psychology, 4(6), 540-547.

Duckworth, A. L., Kirby, T. A., Tsukayama, E., Berstein, H., Ericsson, K. A. (2010) Deliberate practice spells success: Why grittier competitors triumph at the National Spelling Bee. Social Psychological and Personality Science, 2 (2):174-181.

Eskreis-Winkler, L., Shulman, E., Beal, S., \& Duckworth, A. L. (2014). The grit effect: Predicting retention in the military, the workplace, school, and marriage. Frontiers in Psychology, 5, 1-12.

Evans, B. C., Coon, D. W., \& Ume, E. (2011). Use of theoretical frameworks as a pragmatic guide for mixed methods studies: A methodological necessity? Journal of Mixed Methods Research, 5(4), 276-292.

Everett, M. S. (2017). The persistence of Military Veteran students in a Southeastern community college: A narrative study (Doctoral Dissertation). Retrieved from ProQuest. (1960441962).

Forest, J., Mageau, G. A., Sarrazin, C., \& Morin, E. M. (2011). "Work is my passion": The different affective, behavioural, and cognitive consequences of harmonious and obsessive passion toward work. Canadian Journal of Administrative Sciences, 28(1), 27-40.

Frazier, P. A., Lee, R. M., \& Steger, M. F. (2006). What can counseling psychology contribute to the study of optimal human functioning? The Counseling Psychologist, 34(2), 293-303. https://doi.org/10.1177 $/ 0011000005283521$.

Gagne, M., \& Deci, E. (2005). Self-determination theory and work motivation. Journal of Organizational Behavior, 26(4), 331-362.

Greene, J. C. (2007). Mixed methods in social inquiry. San Francisco: Jossey-Bass.

Greenhaus, J. H., Parasuraman, S., \& Wormley, W. M. (1990). Effects of race on organizational experiences, job performance evaluations, and career outcomes. Academy of Management, 33(1), 64-86.

Hoerr, T. R. (2013). Fostering grit : How do I prepare my students for the real world? Alexandria: ASCD. 
Jaskolka, G., Beyer, J. M., \& Trice, H. M. (1985). Measuring and predicting managerial success. Journal of Vocational Behavior, 26(2), 189-205.

Jordan, M. H., Gabriel, T. J., Teasley, R., Walker, W. J., \& Schraeder, M. (2015). An integrative approach to identifying factors related to long-term career commitments: A military example. Career Development International, 20, 163-173. https://doi.org/10.1108/CDI-05-2013-0071.

Joseph, A. I. (2009). The role of grit in predicting performance in collegiate athletes (Doctoral dissertation). Retrieved from ProQuest. (3379578).

Kern, M. L., \& Bowling, D. S. (2015). Character strengths and academic performance in law students. Journal of Research in Personality, 55, 25-29. https://doi.org/10.1016/j.jrp.2014.12.003.

Kets de Vries, M. F. R. (2012). Star performers: Paradoxes wrapped up in enigmas. Organizational Dynamics, 41(3), 173-182.

Kram, K. E., Wasserman, I. C., \& Yip, J. (2012). Metaphors of identity and professional practice: Learning from the scholar-practitioner. Journal of Applied Behavior Science, 48(3), 304-341.

Lent, R. W., \& Brown, S. D. (1996). Social cognitive approach to career development: An overview. Career Development Quarterly, 44(4), 310-321.

Lent, R., \& Brown, S. (2013). Social cognitive model of career self-management: Toward a unifying view of adaptive career behavior across the life span. Journal of Counseling Psychology, 60(4), 557-568.

Lent, R., Brown, S., \& Hackett, G. (1994). Toward a unifying social cognitive theory of career and academic interest, choice, and performance. Journal of Vocational Behavior, 45(1), 79-122.

Lopez, S. J., Pedrotti, J. T., \& Snyder, C. R. (2015). Positive psychology: The scientific and practical explorations of human strengths (3rd ed.). Thousand Oaks: Sage.

Meriac, J. P., Slifka, J. S., \& LaBat, L. R. (2015). Work ethic and grit: An examination of empirical redundancy. Personality and Individual Differences, 86, 401-405.

Miles, M. B., Huberman, A. M., \& Saldaña, J. (2014). Qualitative data analysis: A methods sourcebook (3rd ed.). Los Angeles: Sage.

Nederhof, A. J. (1985). Methods of coping with social desirability bias: A review. European Journal of Social Psychology, 15(3), 263-280. https://doi.org/10.1002/ejsp.2420150303.

Niemiec, R. M. (2017). Character strengths interventions: A field guide for practitioners. Boston: hogrefe.

Peterson, C., \& Seligman, M. E. P. (2004). Character strengths and virtues: A handbook and classification. Oxford: Oxford University Press.

Plano Clark, V. L., \& Ivankova, N. V. (2016). Mixed methods research: A guide to the field. Los Angeles: Sage.

Proctor, C. L., Linley, P. A., \& Maltby, J. (2009). Youth life satisfaction: A review of the literature. Journal of Happiness Studies, 10(5), 583-630.

Robertson, I. T., Cooper, C. L., Sarkar, M., \& Curran, T. (2015). Resilience training in the workplace from 2003 to 2014: A systematic review. Journal of Occupational and Organizational Psychology, 88(3), 533562. https://doi.org/10.1111/joop.12120.

Russell, J. E. (2008). Promoting subjective well-being at work. Journal of Career Assessment, 16(1), 117-131.

Ryan, R. M., \& Deci, E. L. (2000). Self-determination theory and the facilitation of intrinsic motivation, social development, and well-being. The American Psychologist, 55(1), 68-78.

Ryan, R., \& Deci, E. (2001). On happiness and human potentials: A review of research on hedonic and eudaimonic well-being. Annual Review of Psychology, 52(1), 141-166.

Schon, D. (1987). Educating the reflective practitioner. San Francisco: Jossey-Bass.

Seligman, M. E. P. (2011). Flourish: A visionary new understanding of happiness and well-being. New York: Free Press.

Seligman, M. E., \& Csikszentmihalyi, M. (2000). Positive psychology: An introduction. The American Psychologist, 55(1), 5-14.

Sheldon, K. M., \& Ryan, R. M. (2011). Positive psychology and self-determination theory: A natural interface. In V. I. Chirkov, R. M. Ryan, \& K. M. Sheldon (Eds.), Human autonomy in cross-cultural context: Perspectives on the psychology of agency, freedom, and well-being (pp. 33-44). London: Springer.

Stewart, S. B. (2015). Grit and self-control as predictors of first-year student success (doctoral dissertation). Retrieved from PQDT Open (3722559).

Strayhorn, T. (2014). What role does grit play in the academic success of black male collegians at predominantly white institutions? Journal of African American Studies, 18(1), 1-10.

Teddlie, C. B., \& Tashakkori, A. M. (2009). Foundations of mixed methods research: Integrating quantitative and qualitative approaches in the social and behavioral sciences. Thousand Oaks: Sage. 
Tough, P. (2012). How children succeed : Grit, curiosity, and the hidden power of character. Boston: Houghton Mifflin Harcourt.

U.S. Department of Labor (2013). Labor force statistics from the current population survey. Retrieved January 15, 2015, from www.bls.gov/cps/cpsaat1.htm

Von Culin, K. R., Tsukayama, E., \& Duckworth, A. L. (2014). Unpacking grit: Motivational correlates of perseverance and passion for long-term goals. Journal of Positive Psychology, 9(4), 306-312. https://doi.org/10.1080/17439760.2014.898320.

Publisher's Note Springer Nature remains neutral with regard to jurisdictional claims in published maps and institutional affiliations. 